\title{
Effect of Methamphetamine on Cognitive Functions of Adult Female Rats Prenatally Exposed to the Same Drug
}

\author{
E. MACÚCHOVÁ ${ }^{1}$, K. NOHEJLOVÁ-DEYKUN ${ }^{1}$, R. ŠLAMBEROVÁ ${ }^{1}$ \\ ${ }^{1}$ Department of Normal, Pathological and Clinical Physiology, Third Faculty of Medicine, Charles \\ University in Prague, Prague, Czech Republic
}

Received March 16, 2013

Accepted June 24, 2013

\begin{abstract}
Summary
The aim of this study was to investigate the effect of prenatal methamphetamine (MA) exposure and application of the same drug in adulthood on cognitive functions of adult female rats. Animals were prenatally exposed to MA $(5 \mathrm{mg} / \mathrm{kg})$ or saline (control group). The cognitive function was tested as ability of spatial learning in the Morris Water Maze (MWM). Each day of the experiment animals received an injection of MA $(1 \mathrm{mg} / \mathrm{kg})$ or saline. Our results demonstrated that prenatal MA exposure did not affect the latency to reach the hidden platform or the distance traveled during the Place Navigation Test; however, the speed of swimming was increased in prenatally MA-exposed rats compared to controls regardless of the treatment in adulthood. MA treatment in adulthood increased the latency and distance when compared to controls regardless of the prenatal exposure. Neither prenatal exposure, nor treatment in adulthood affected memory retrieval. As far as the estrous cycle is concerned, our results showed that prenatally MA-exposed females in proestrus/estrus swam faster than females in diestrus. This effect of estrous cycle was not apparent in control females. In conclusion, our results indicate that postnatal, but not prenatal exposure to MA affects learning of adult female rats.
\end{abstract}

\section{Key words}

Morris Water Maze - Methamphetamine - Spatial learning • Memory • Sensitization • Estrous cycle

\section{Corresponding author}

Romana Šlamberová, Department of Normal, Pathological and Clinical Physiology, Third Faculty of Medicine, Ke Karlovu 4, 12000 Prague 2, Czech Republic.

E-mail: romana.slamberova@lf3.cuni.cz

\section{Introduction}

Methamphetamine (MA) is one of the most frequently used illicit drugs in the Czech Republic, due to its relatively uncomplicated production, and its low price in comparison with cocaine or heroin (Vavř́nková et al. 2001). MA belongs to a group of highly addictive psychostimulant drugs (Marwick 2000). Roughly half of MA users are women in reproductive age, who would continue using the drug also during pregnancy (Williams et al. 2003a). Even though, the long-term effects of prenatal exposure of MA remain relatively unclear, some studies suggest that prenatal MA exposure impairs the development of the CNS of the neonate (Šlamberová et al. 2006, Williams et al. 2003a).

Psychostimulant drugs activate molecular signalization in dopaminergic and glutamatergic pathways, which are widely distributed in the brain (e.g., basal ganglia, nucleus accumbens, and prefrontal cortex) (Kelley 2004). Previously we demonstrated that an acute administration of MA causes an increase in the dopamine level in the nucleus accumbens (Bubeníková-Valešová et al. 2009). Dopamine pathways are involved in motor control, reward circuits, sexual behavior, affective state and cognition (Camp and Robinson 1988).

It is known that prenatal MA exposure leads to long-term behavioral effects on spatial learning (AcuffSmith et al. 1996). Brain regions, which are involved in the process of learning and memory, develop relatively late compared to other structures. Substantial remodeling and growth of rat hippocampus and related structures begin on embryonic day (ED) 14 and continue until postnatal day (PD) 19. The brain of neonatal rats (PD 1120), which approximates human brain development 
during the second and third trimester is highly vulnerable to pharmacological effects (Rice and Barone 2000). Repeated exposure of neonates to high doses of MA (15 and $20 \mathrm{mg} / \mathrm{kg}$ ) lead to long-term cognitive deficits in spatial learning, which are associated with structural changes within the hippocampus (Williams et al. 2003b).

The effect of psychostimulants is affected by the stages of CNS development. Vorhees et al. (2005) found that MA exposure of adolescent rats (PD 40-60) causes deficits in spatial learning when tested in adulthood. Other study demonstrated that exposure to MA during preadolescence improves spatial learning in male rats (Moenk and Matuszewich 2012). In addition, our previous study (Schutová et al. 2008) demonstrated that prenatal MA exposure $(5 \mathrm{mg} / \mathrm{kg})$ does not affect learning in the Morris Water Maze (MWM) (Morris et al. 1982) and that MA treatment in adulthood $(1 \mathrm{mg} / \mathrm{kg})$ impairs learning in terms of changing search strategies. In humans, however, prenatal MA exposure during this critical period of development leads to long-term cognitive deficits (Chang et al. 2004, Smith et al. 2001).

Some laboratories (Crozatier et al. 2003, Stanwood and Levitt 2003) including our own (Šlamberová et al. 2011b) have investigated a phenomenon defined as behavioral sensitization or reverse tolerance (Suzuki et al. 2004) induced by prenatal drug exposure. The results are rather inconsistent. While Crozatier et al. (2003) demonstrated cocaine-induced sensitization in mice to cocaine exposure in adulthood, Stanwood and Levitt (2003) showed behavioral tolerance to the challenge dose of amphetamine in rabbits prenatally (ED 16-25) exposed to cocaine. Our results showed a sensitizing effect of prenatal MA exposure to MA treatment in adulthood (Bubeníková-Valešová et al. 2009, Šlamberová et al. 2011a, b).

In most of the studies male rats are used for investigation the effects of drug exposure on behavioral patterns. However, as other studies suggest, sexual differences in the drug sensitivity are important to be taken into consideration (Roth et al. 2002, Schutová et al. 2013). Female rats have been shown to be more sensitive to amphetamine (Becker 1999, Bisagno et al. 2003), MA (Schindler et al. 2002) and cocaine (Cailhol and Mormede 1999) when compared to male rats. In addition, females differ in spatial learning across the estrous cycle (Berry et al. 1997, Warren and Juraska 1997). There are only a few studies available that examined the differences in the drug sensitivity of female rats across their estrous cycle. Most of them are focused on behavioral responses to psychostimulants influenced by ovarian hormones (Becker 1990, Peris et al. 1991). For example, Sell et al. (2000) reported hyperactivity caused by cocaine in female rats in proestrus and estrus.

We already published in our previous study (Schutová et al. 2008), how does the MA (1 mg/kg) administration affect the spatial learning and memory tested in the MWM in adult male rats prenatally exposed to MA ( $5 \mathrm{mg} / \mathrm{kg})$. To see the possible sex differences, the present study will examine the changes induced by prenatal and adult MA administration in female rats. The study was designed to test the following four objectives: 1) the effect of prenatal MA exposure and 2) the effect of MA administration in adulthood on cognitive functions of female rats; 3 ) the possible sensitizing effect of prenatal MA exposure; 4) the different drug sensitivity of females across the estrous cycle.

\section{Materials and Methods}

\section{Animals and drug injections}

Adult female Wistar rats were delivered by Anlab (Prague, the Czech Republic) from Charles River Laboratories International, Inc. Animals were then left undisturbed for a week. After the acclimatization period females were smeared by vaginal lavage to determine the phase of their estrous cycle.

When the onset of estrous phase was determined, females were housed overnight with sexually mature males. There were always one female and one male per cage. The following morning they were smeared for the presence of sperms and returned to their home cages. The day when sperms were detected was designated as day 1 of gestation. Most of the females were successful in pregnancy induction. The successful impregnation did not differ between females with MA or saline application. The total number of pregnant females was 20. Animals were randomly assigned to two treatment groups through the entire gestation period: 10 MA-treated (MA, $5 \mathrm{mg} / \mathrm{kg}$ ) and 10 saline-treated (SA) (Šlamberová et al. 2005). The dose $5 \mathrm{mg} / \mathrm{kg}$ of methamphetamine (MA) was chosen because it induces similar fetal brain drug concentrations and similar behavioral changes to those found in humans (AcuffSmith et al. 1996). They were injected subcutaneously (s.c.). The day of delivery was counted as PD 0. All litters were adjusted to twelve. To avoid litter bias pups were cross-fostered so that each mother had six MA-treated pups ( 3 males and 3 females) and six saline-treated pups 
(3 males and 3 females). There were no differences in weights of the pups from prenatally MA- and SAexposed groups after birth and during lactation period. On PD 21, animals were weaned and housed in groups, separated according to sex (4 males and 5 females, respectively, per cage). They were left undisturbed until adulthood. Always one prenatally SA-exposed and one prenatally MA-exposed female from each litter were used for the experiment to avoid litter effects. The rest of the animals were used in other studies.

\section{Estrous cycle determination}

Every day prior to testing each female was smeared by vaginal lavage. The smear was then examined by light microscopy. According to Turner and Bagnara (1976) two phases of the estrous cycle were recognized in the present study: proestrus/estrus $(\mathrm{P} / \mathrm{E})$ with predominance of large nucleated and some cornified epithelial cells in the smear; diestrus (D) with predominance of leukocytes in the smear. The estrous cycle of a female rat lasts for 4 to 5 days (Turner and Bagnara 1976). We did not find any differences in the estrous cycle between prenatally MA-exposed and prenatally SA-exposed females.

\section{MWM testing}

40 adult female rats (PD 60-90) were tested over a 12-day period. To determine the effect of MA in adulthood half of the females from each prenatal treatment (MA, $\mathrm{n}=10 ; \mathrm{SA}, \mathrm{n}=10$ ) received a low dose of MA (1 mg/kg) s.c. after finishing testing each day. The other half (MA, $n=10 ; \mathrm{SA}, \mathrm{n}=10$ ) was exposed to an injection of saline $(1 \mathrm{ml} / \mathrm{kg})$. The dose $1 \mathrm{mg} / \mathrm{kg}$ of MA was used because it does not cause stereotypical behavior (unpublished data), unlike the dose of $5 \mathrm{mg} / \mathrm{kg}$, which was used in gestation. This dose is often used as challenge dose in the test of behavioral sensitization (Suzuki et al. 2004). The animals also received MA and SA on the days when no tests were performed. The timing of injections was the same as in the days of testing.

Three types of tests were used in this study: the Place Navigation Test, the Probe Test and the Retention Memory Test. Before each experiment animals were left to acclimate to the laboratory conditions, in which the experiments were performed.

\section{Apparatus}

The water maze consisted of a blue circular tank
( $2 \mathrm{~m}$ in diameter), filled with water $\left(22.5 \pm 2.5^{\circ} \mathrm{C}\right)$. The maze was divided into four quadrants in respect to start positions (north-N, south-S, east-E and west-W). A transparent circular platform was placed into the NE quadrant of the tank, $1 \mathrm{~cm}$ below the water surface. The maze was surrounded by various extra-maze cues on the walls. Trials were tracked using a video-tracking system EthoVision 6 (Noldus Information Technology, Netherlands).

\section{The Place Navigation Test}

During 6 days of spatial learning animals were trained to locate the hidden platform within the limit of $60 \mathrm{~s}$. If the animal did not reach the platform within the limit, it was gently guided by the experimenter to the platform. Eight trials per day were performed. The position of the platform was the same through the period of learning. After each trial, the rat was remained on the platform for $30 \mathrm{~s}$ prior to the next trial to have a chance to orientate and to learn its position in the room. After the trials on each experimental day, the animal received the s.c. injection of MA or saline as appropriate and was placed in the home cage.

The following parameters were evaluated with the use of EthoVision program: latency of platform acquisition [s], distance traveled (the length of the swimpath) $[\mathrm{cm}]$ and speed of swimming $[\mathrm{cm} / \mathrm{s}]$.

Search strategies (swimming pathways) of individual animals were manually analyzed after track acquisition on days 1, 3, 6 and 12. The following search strategies were assigned (Schutová et al. 2009): 1) thigmotaxis - predominant swimming along the wall of the pool; 2) random search - swimming over the entire area of the pool in straight swims or in wide circular swims; 3) scanning - swimming over the central area of the pool; 4) search in an incorrect quadrants - direct swim to an incorrect quadrant of the pool followed by loops and turns there; 5) search in a correct quadrant direct swim to a correct quadrant of the pool followed by loops and turns there, 6) spatial search - direct swim path to the platform. Analysis of search strategies was aiming on better understanding of differences in process of learning in animals exposed to MA either prenatal or acute.

\section{The Probe Test}

During the Probe Test, which was conducted on the 8th day, the platform was removed, and the animal was left to swim in the pool for $60 \mathrm{~s}$. The start position in 

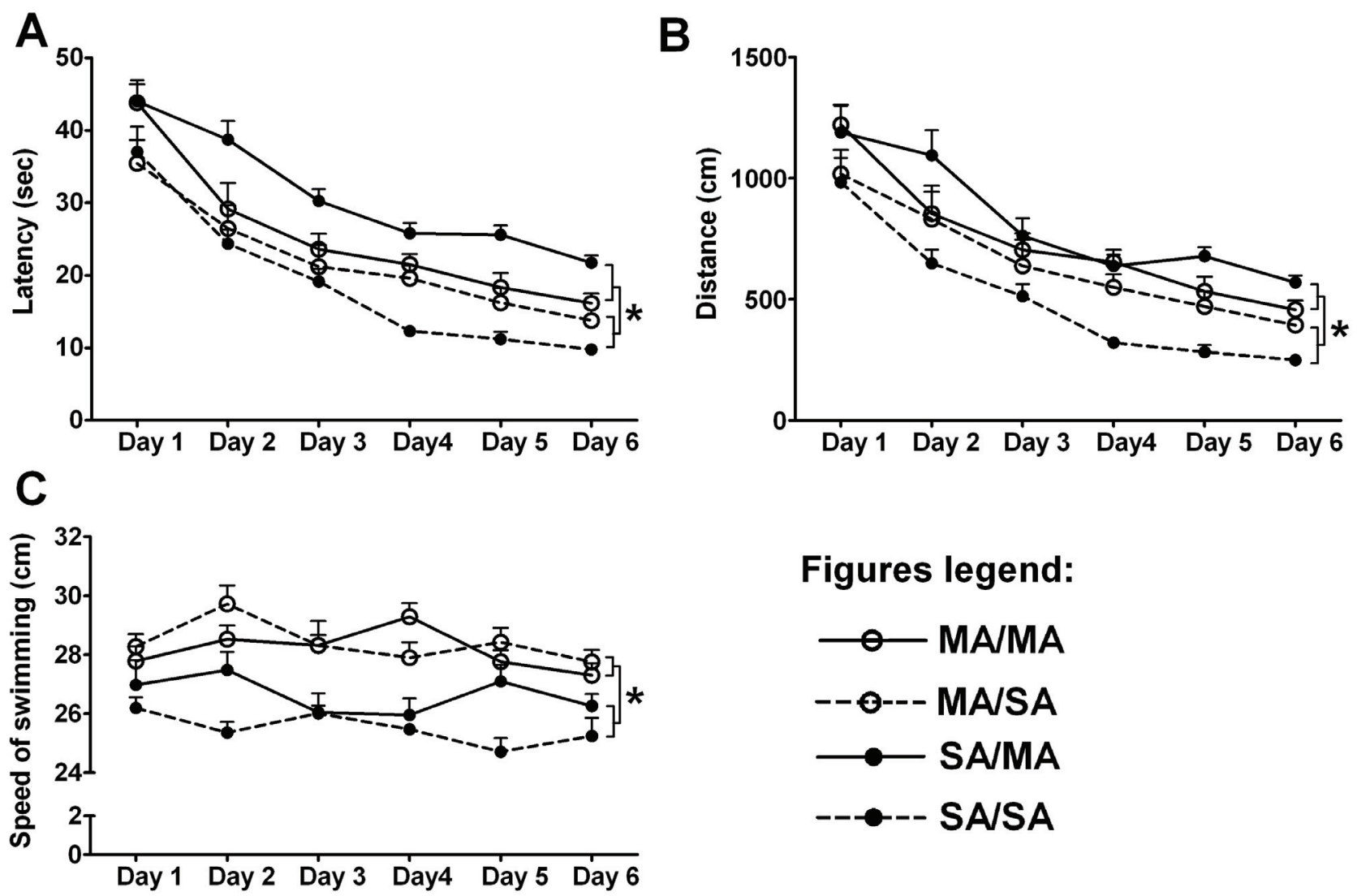

Figures legend:

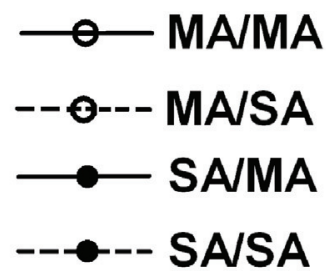

Fig. 1. Effect of prenatal and adult MA exposure on performance in the Place Navigation Test. A. Latency of platform acquisition - main effect of MA application in adulthood, * $p<0.05$. B. Distance traveled - main effect of MA application in adulthood, $* p<0.05$. C. Speed of swimming - main effect of prenatal MA exposure. Results are presented as mean + SEM, $n=10$.

this test was for each animal north $(\mathrm{N})$. The following parameters were recorded: frequency and duration [s] of presence in the quadrant where the platform was located, frequency of swimming across the former placement of the platform and speed of swimming $[\mathrm{cm} / \mathrm{s}]$.

\section{The Retention Memory Test}

The memory test was performed on the 12th day. An animal was supposed to find the platform located at the same position as in the learning test within $60 \mathrm{~s}$. Each animal was subjected to 8 trials. The same parameters were analyzed as in the Place Navigation Test: latency of platform acquisition [s], distance traveled [cm] and speed of swimming $[\mathrm{cm} / \mathrm{s}]$.

\section{Statistical analysis}

The data from the Place Navigation Test were analyzed by a Two-Way ANOVA (Prenatal exposure $\mathrm{x}$ Treatment in adulthood) with multilevel repeated measure (days $x$ trials/day). Probe Test data were analyzed by a Three-Way ANOVA (Prenatal exposure $\mathrm{x}$
Treatment in adulthood $x$ Estrous cycle). A Three-Way ANOVA (Prenatal exposure $\mathrm{x}$ Treatment in adulthood $\mathrm{x}$ Estrous cycle) with repeated measure (trials) was used to analyze the data from the Retention Memory Test. The Bonferroni test was used for post-hoc comparisons. The $\mathrm{X}^{2}$ test was used to analyze the occurrence of the search strategies. In all tests, the differences were considered significant if $\mathrm{p}<0.05$.

\section{Results}

\section{The Place Navigation Test}

For the latency of platform acquisition (Fig. 1A) and the distance traveled (Fig. 1B) the main effect of MA treatment in adulthood was demonstrated [latency: $\mathrm{F}(1,36)=6.28, \mathrm{p}<0.05$; distance traveled: $\mathrm{F}(1,36)=6.33$, $\mathrm{p}<0.05]$. On average the animals with MA treatment in adulthood had longer latencies and they had longer trajectories when compared to controls, regardless of the prenatal exposure. The speed of swimming was not affected by MA treatment in adulthood $[\mathrm{F}(1,36)=0.52, \mathrm{p}=0.47]$. 


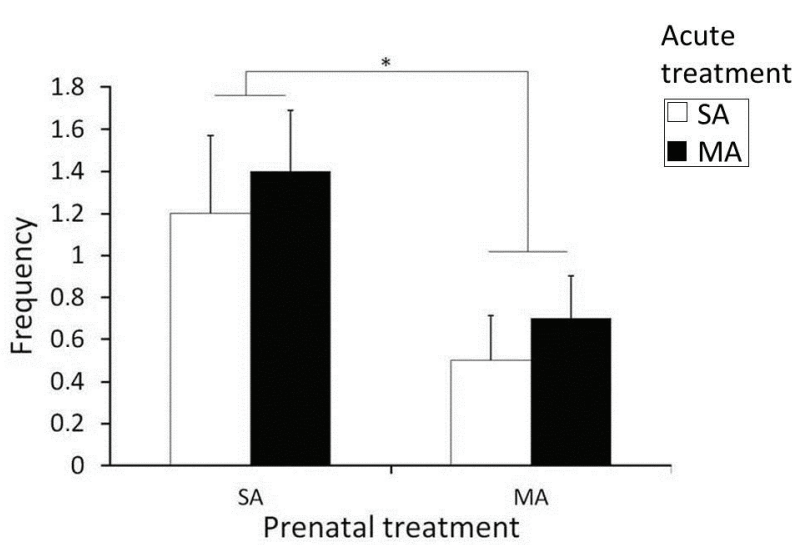

Fig. 2. Effect of prenatal and adult MA exposure on frequency of swimming across the former placement of the hidden platform in the Probe Test. Values are mean + SEM, $n=10 . * p<0.05-$ main effect of prenatal exposure: MA group has lower frequency than SA group.

Prenatal MA exposure did not affect the latency to find the hidden platform $[\mathrm{F}(1,36)=0.19, \mathrm{p}=0.66]$ or the distance traveled $\mathrm{F}(1,36)=0.16, \mathrm{p}=0.69]$. However, the main effect of prenatal MA exposure for swimming speed was found $[\mathrm{F}(1,36)=5.68, \mathrm{p}<0.05]$, animals prenatally exposed to MA, swam faster than animals prenatally exposed to saline (Fig. 1C), regardless of postnatal exposure.

All animals, regardless of prenatal or postnatal treatment, demonstrated learning ability over the 6-day test period as represented by a decrease in latency: $[\mathrm{F}(5,180)=86.69, \mathrm{p}<0.0001]$ and distance traveled: $[\mathrm{F}(5,180)=91.40, \mathrm{p}<0.0001]$. The speed of swimming did not differ between days $[\mathrm{F}(5,180)=1.28, \mathrm{p}=0.28]$. There was no interaction between prenatal and adult drug exposure in the latency $[\mathrm{F}(1,36)=2.21, \mathrm{p}=0.14]$, distance traveled $[\mathrm{F}(1,36)=2.09, \mathrm{p}=0.15]$ or speed of swimming $[\mathrm{F}(1,36)=0.61, \mathrm{p}=0.43]$.

\section{The Probe Test}

Analysis of the data from the Probe Test showed a significant main effect of prenatal MA exposure on the frequency of swimming across the former placement of the hidden platform $[\mathrm{F}(1,32)=4.68, \mathrm{p}<0.05]$. Female rats prenatally exposed to MA swam less often across the former placement of the hidden platform than prenatal controls (Fig. 2). This measure was not affected by treatment in adulthood $[\mathrm{F}(1,32)=0.65, \mathrm{p}=0.42]$.

There was no significant effect of the frequency or the duration of presence in the quadrant where the hidden platform was placed during the learning phase.
A

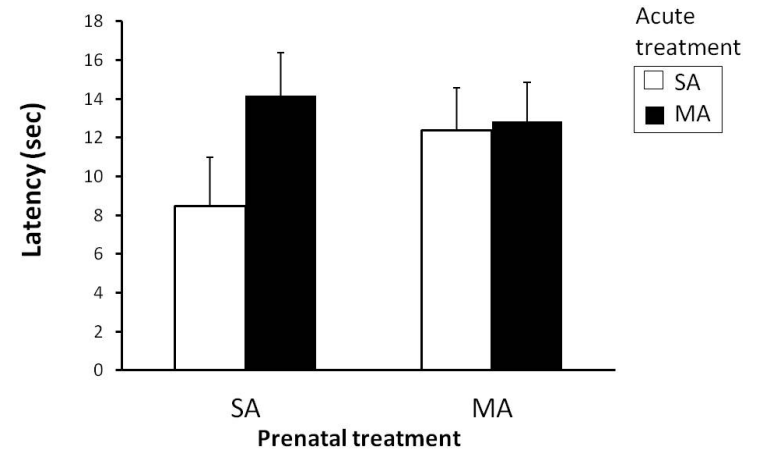

C
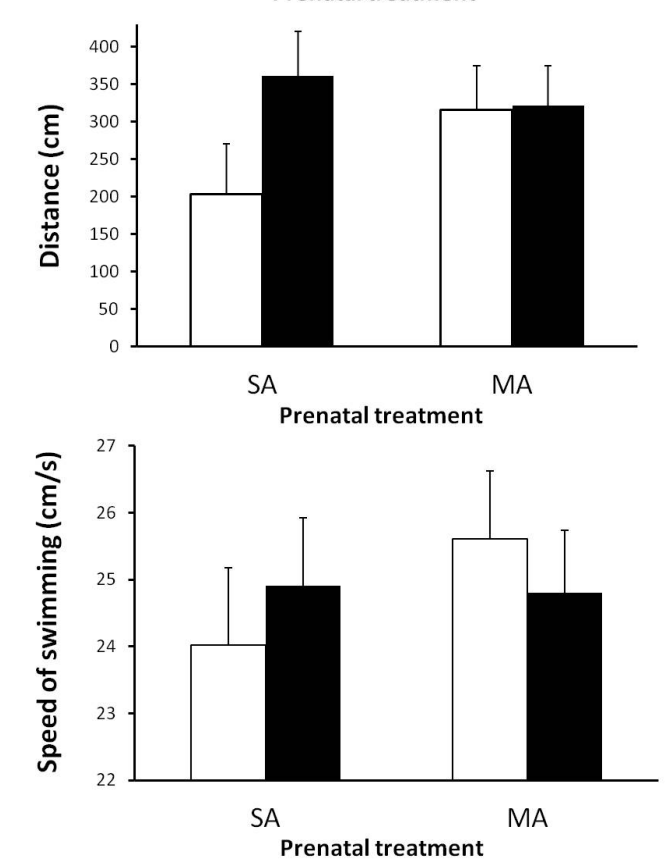

Fig. 3. Effect of prenatal and adult MA exposure on performance in the Retention Memory Test. A. Latency of platform acquisition. B. Distance traveled. C. Speed of swimming. Results are presented as mean + SEM, $n=10$.

\section{The Retention Memory Test}

Statistical analysis of data from Retention Memory Test showed no significant differences between animals exposed to MA with controls in either of the parameters (Fig. 3).

\section{Search strategies}

The strategies of swimming to find the hidden platform differed based on the prenatal and adult drug exposure and changed as the time of the experiment progressed.

On Day 1 of the experiment, prenatally MAexposed rats injected in adulthood with MA preferred thigmotaxis (predominant swimming along the wall of the pool) more than any other groups ( $\mathrm{SA} / \mathrm{SA}=12.5 \%$, $\mathrm{SA} / \mathrm{MA}=30 \%, \quad \mathrm{MA} / \mathrm{SA}=22.5 \%, \quad \mathrm{MA} / \mathrm{MA}=50 \%$ ) $\left[\chi^{2}=29.54, p<0.0001\right]$. On the other hand, they used at 
least from all the groups (SA/SA $=12.5 \%, \mathrm{SA} / \mathrm{MA}=20 \%$, $\mathrm{MA} / \mathrm{SA}=18.75 \%, \quad \mathrm{MA} / \mathrm{MA}=8.75 \%$ ) the strategy of scanning (swimming over the central area of the pool) $\left[\chi^{2}=24.95, \mathrm{p}<0.0001\right]$.

On Day 3, the percentage changed, but the difference in using strategies stayed significant between groups. Thigmotaxis was still used the most (SA/SA $=0 \%, \quad \mathrm{SA} / \mathrm{MA}=12.5 \%, \quad \mathrm{MA} / \mathrm{SA}=5 \%$, $\mathrm{MA} / \mathrm{MA}=37.5 \%)\left[\chi^{2}=53.66, \mathrm{p}<0.0001\right]$ and scanning the least $(\mathrm{SA} / \mathrm{SA}=30 \%, \mathrm{SA} / \mathrm{MA}=30 \%, \mathrm{MA} / \mathrm{SA}=37.5 \%$, $\mathrm{MA} / \mathrm{MA}=15 \%)\left[\chi^{2}=10.57, \mathrm{p}<0.05\right]$ by prenatally MAexposed rats injected with MA in adulthood.

On Day 6, control group already displayed prevalence of spatial search (direct swim path to the platform) when compared to MA-treated groups $(\mathrm{SA} / \mathrm{SA}=60 \%, \quad \mathrm{SA} / \mathrm{MA}=43.75 \%, \quad \mathrm{MA} / \mathrm{SA}=27.5 \%$, $\mathrm{MA} / \mathrm{MA}=25 \%)\left[\chi^{2}=26.61, \mathrm{p}<0.0001\right]$. On the other hand, prenatally MA-exposed rats injected in adulthood with MA used still the thigmotaxis the most (SA/SA $=12.5 \%$, $\mathrm{SA} / \mathrm{MA}=12.5 \%, \quad \mathrm{MA} / \mathrm{SA}=30 \%, \quad \mathrm{MA} / \mathrm{MA}=43.75 \%$ ) $\left[\chi^{2}=29.63, p<0.0001\right]$.

On Day 12 (the Retention Memory Test), prenatally saline-exposed rats preferred the spatial search strategy, while prenatally MA-exposed rats did not $(\mathrm{SA} / \mathrm{SA}=63.75 \%, \quad \mathrm{SA} / \mathrm{MA}=60 \%, \quad \mathrm{MA} / \mathrm{SA}=35 \%$, $\mathrm{MA} / \mathrm{MA}=33.75 \%)\left[\chi^{2}=24.48, \mathrm{p}<0.0001\right]$. In contrast, both groups of prenatally MA-exposed rats still used the thigmotaxis $\quad(\mathrm{SA} / \mathrm{SA}=3.75 \%, \quad \mathrm{SA} / \mathrm{MA}=12.5 \%$, $\mathrm{MA} / \mathrm{SA}=35 \%, \mathrm{MA} / \mathrm{MA}=28.75 \%)\left[\chi^{2}=31.09, \mathrm{p}<0.0001\right]$.

\section{Effect of the estrous cycle}

There were no differences induced by the estrous cycle in any measures in the Place Navigation Test, or in the Probe Test.

In the Retention Memory Test, there were no differences in the latency of platform acquisition or the distance traveled, but there was an interaction between prenatal drug exposure and the estrous cycle in the speed of swimming $[\mathrm{F}(1,32)=4.17, \mathrm{p}<0.05]$. The data showed that prenatally MA-exposed animals in $\mathrm{P} / \mathrm{E}$ swam faster than prenatally MA-exposed rats in $\mathrm{D}(\mathrm{p}<0.05)$. In prenatally saline-exposed rats, no such difference was apparent.

\section{Discussion}

The dose of MA ( $5 \mathrm{mg} / \mathrm{kg})$ that was used in the present study for the prenatal exposure is a standard dose used in our experiments (Šlamberová et al. 2005). This dose was chosen because it induces fetal brain drug concentrations and behavioral changes similar to those found in humans (Acuff-Smith et al. 1996). Even though it was found that daily maternal application of MA in a dose of $5 \mathrm{mg} / \mathrm{kg}$ may delay sensorimotor development (Martin et al. 1976, Šlamberová et al. 2006), the motor skills are not affected in adulthood (Hrubá et al. 2010). In addition, the low dose of MA $(1 \mathrm{mg} / \mathrm{kg})$ injected in adulthood does not induce stereotypical behavior and, therefore, it should not affect the swimming of the tested animal. To avoid any possible impairing effects of acute MA administration on swimming in the present study MA was injected into the animal each day after the MWM performance. From all of the above, the results that we can see in the present study are clearly due to the effect of both, prenatal MA exposure and MA adult treatment, on cognitive functions of the rat independently from the animals' ability to move or swim.

The first goal of the present study was to determine the effect of prenatal MA exposure on learning abilities of female rats. When analyzing data from the Place Navigation Test we did not find any effect of prenatal MA exposure (5 mg/kg daily) on the latency of platform acquisition or the distance traveled. These results are in accordance with our previous study on male rats (Schutová et al. 2009). Data from the Probe Test showed that animals with prenatal MA-exposure had lower frequency of swimming across the former placement of the hidden platform. This finding disagrees with our previous study (Schutová et al. 2009), in which no effect of prenatal MA exposure on the performance in the Probe Test was found. This discrepancy may be assigned to sex differences. The Probe Test is a good way of analysis of the memory recall quality. According to Brown et al. (2000), if the animal uses a non-spatial strategy during the learning phase, it usually fails in the Probe Test. Therefore, our data from the Probe Test suggest that the prenatal MA exposure may impair learning. These data is in agreement with study on neonates that were exposed to MA and tested in adulthood, showing reduction of performance in the Probe Test (Vorhees et al. 2000, Williams et al. 2003b). We did not find any effect of prenatal treatment in the Retention Memory Test. Thus, we could say that prenatal MA treatment does not influence memory in the MWM, which is in accordance with study of Acuff-Smith et al. (1999).

The second goal of the present study was to determine the effect of MA treatment in adulthood. Data 
from the Place Navigation Test showed that animals with MA exposure in adulthood swam longer distances and had longer latencies to reach the hidden platform, regardless of the prenatal treatment. Schutová et al. (2008, 2009) reported that MA treatment in adulthood prolonged distance traveled, but did not have any effect on the latency. Our findings are in accordance with the results of Friedman et al. (1998), who showed learning impairment in the MWM after acute MA exposure at the neurotoxic MA dose of $12.5 \mathrm{mg}$. Additionally, Camarasa et al. (2010) found out that rats treated with MA $(10 \mathrm{mg} / \mathrm{kg})$ in adulthood show increased latencies platform acquisition. The results from the Retention Memory Test did not show any effect of MA exposure in adulthood on the ability of the animal to memorize the platform's position. These results correspond to results of Cao et al. (2013) showing no effect of MA (1 mg/kg) on spatial memory in mice exposed to learning for 5 consecutive days and then tested for the memory reconsolidation.

The speed of swimming seems to have the positive correlation to the motivation of the animal to find the platform in the MWM (Lubbers et al. 2007). In addition, it has been suggested that motivation is mediated by the meso-accumbens dopamine system (Salamone and Correa 2002) and this system might be affected by MA application in adulthood. We did not find any effect of MA exposure in adulthood on the speed of swimming, which does not coincide with our previous results from MWM (Schutová et al. 2008, 2009). On the other hand, the results from the Place Navigation Test showed that prenatal MA-exposure resulted in an increase of speed of swimming. Females prenatally exposed to MA swam faster than animals with prenatal saline exposure, regardless of treatment in adulthood. Thus, it might be that prenatally MA-exposed rats had higher motivation than control rats. Another reason might be that prenatal MA exposure increases locomotor activity (Bubeníková-Valešová et al. 2009), similarly as exposure to another psychostimulants, such as cocaine (Peris et al. 1992).

The third goal of the present study was to evaluate possible sensitizing effect of prenatal MA exposure to the same drug administered in adulthood. Our previous results showed sensitizing effect of prenatal MA exposure to the same drug treatment in adulthood on locomotion or drug-seeking behavior (BubeníkováValešová et al. 2009, Šlamberová et al. 2011a, b). Additionally, we showed that the sensitizing effect of prenatal MA in males corresponds with dopamine levels in the nucleus accumbens (Bubeníková-Valešová et al. 2009). The present study examining cognition in female rats showed no effect of prenatal MA exposure on behavioral sensitization to MA treatment in adulthood that would coincide with results in the report of Schutová et al. (2009). The reason might be due to sex differences (Melnick and Dow-Edwards 2001, Peris et al. 1992). Nevertheless, even though we did not see any sensitizing effect of prenatal MA exposure in the latency or distance traveled, in search strategies the sensitizing effect was apparent. Specifically, we found that prenatally MAexposed rats injected in adulthood with MA had higher incidence of thigmotaxis across the days of experiment than any other groups. Search strategies are used as alternative measures to the latency to better recognize the differences in spatial learning (Gallagher et al. 1993, Janus 2004). In some cases it may happen that two animals with the same lengths of latencies use different strategies of swimming; further one animal might use a strategy to find the hidden platform without obtaining knowledge of the platform's location (non-spatial strategy). Usually, animals use the non-spatial strategy in the beginning and spatial search at the end of the learning period when the animal remembers the exact location of the platform (Janus 2004).

The last goal of the present study was to investigate how the drug sensitivity of females differs across the estrous cycle. Our results from the Retention Memory Test showed that prenatally MA-exposed animals swam faster in proestrus/estrus than in diestrus. To the best of our knowledge, there is no literature available showing effect of prenatal or acute MA exposure on spatial learning tested in the MWM in female rats. Our unpublished data demonstrated that females (especially in proestrus/estrus) displayed sensitization induced by prenatal MA exposure to adult administration of amphetamine or MDMA. In addition, study of Becker (1999) showed that estrogen and progesterone affect the striatal dopamine function. Female rats show a greater behavioral response when the striatal dopaminergic system is stimulated in the estrus instead of in the diestrus (Becker et al. 1982). Thus, future studies are planned to test the sensitizing effect of MA on the striatal dopaminergic system of female rats in respect of their estrous cycle.

In conclusion, the present study on adult female rats demonstrates that prenatal exposure to MA $(5 \mathrm{mg} / \mathrm{kg})$ neither affects learning, nor memory. On the other hand, 
we showed that MA treatment in adulthood impairs learning. As a matter of sensitization, the present data demonstrate that the sensitizing effect of prenatal MA exposure to the same drug exposure in adulthood was apparent only in strategies, but not in the time or length that was necessary to find the hidden platform. Furthermore, we suggest that sensitivity to prenatal MA exposure might be related to the hormonal cycle of females. As there are no studies investigating the effect of MA exposure on females' cognitive functions during the estrous cycle, our study might contribute to further understanding of this issue. Our future experiments will test the cognitive functions in animals prenatally exposed to MA in shorter time periods, affecting development during individual trimesters. From this we will try to find the critical period for the long-term consequences caused by MA exposure.

\section{Conflict of Interest}

There is no conflict of interest.

\section{Acknowledgements}

This study was supported by grant GA 305/09/0126 from Grant Agency of the Czech Republic, project CSM 31 from Ministry of Education, Youth and Sports and research program PRVOUK P34, GAUK 545212 and 266705/SVV/2013 from Charles University in Prague. The procedures for animal experimentation utilized in this report was reviewed and approved by the Institutional Animal Care and Use Committee and is in agreement with the Czech Government Requirements under the Policy of Humans Care of Laboratory Animals (No. 246/1992) and with the regulations of the Ministry of Agriculture of the Czech Republic (No. 311/1997).

\section{Abbreviations}

MA - methamphetamine; SA - saline; CNS - central nervous system; MWM - Morris Water Maze; PD postnatal day; P/E - proestrus/estrus; D - diestrus; s.c. subcutaneously; NE quadrant - north-east quadrant

\section{References}

ACUFF-SMITH KD, SCHILLING MA, FISHER JE, VORHEES CV: Stage-specific effects of prenatal d-methamphetamine exposure on behavioral and eye development in rats. Neurotoxicol Teratol 18: 199-215, 1996.

BECKER JB: Estrogen rapidly potentiates amphetamine-induced striatal dopamine release and rotational behavior during microdialysis. Neurosci Lett 118: 169-171, 1990.

BECKER JB: Gender differences in dopaminergic function in striatum and nucleus accumbens. Pharmacol Biochem Behav 64: 803-812, 1999.

BECKER JB, ROBINSON TE, LORENZ KA: Sex differences and estrous cycle variations in amphetamine-elicited rotational behavior. Eur J Pharmacol 80: 65-72, 1982.

BERRY B, MCMAHAN R, GALLAGHER M: Spatial learning and memory at defined points of the estrous cycle: effects on performance of a hippocampal-dependent task. Behav Neurosci 111: 267-274, 1997.

BROWN RW, BARDO MT, MACE DD, PHILLIPS SB, KRAEMER PJ: D-amphetamine facilitation of morris water task performance is blocked by eticlopride and correlated with increased dopamine synthesis in the prefrontal cortex. Behav Brain Res 114: 135-143, 2000.

BUBENÍKOVÁ-VALEŠOVÁ V, KAČER P, SYSLOVÁ K, RAMBOUSEK L, JANOVSKÝ M, SCHUTOVÁ B, HRUBÁ L, ŠLAMBEROVÁ R: Prenatal methamphetamine exposure affects the mesolimbic dopaminergic system and behavior in adult offspring. Int J Dev Neurosci 27: 525-530, 2009.

CAILHOL S, MORMEDE P: Strain and sex differences in the locomotor response and behavioral sensitization to cocaine in hyperactive rats. Brain Res 842: 200-205, 1999.

CAMARASA J, RODRIGO T, PUBILL D, ESCUBEDO E: Memantine is a useful drug to prevent the spatial and nonspatial memory deficits induced by methamphetamine in rats. Pharmacol Res 62: 450-456, 2010.

CAMP DM, ROBINSON TE: Susceptibility to sensitization. II. The influence of gonadal hormones on enduring changes in brain monoamines and behavior produced by the repeated administration of D-amphetamine or restraint stress. Behav Brain Res 30: 69-88, 1988. 
CAO G, ZHU J, ZHONG Q, SHI C, DANG Y, HAN W, LIU X, XU M, CHEN T: Distinct roles of methamphetamine in modulating spatial memory consolidation, retrieval, reconsolidation and the accompanying changes of ERK and CREB activation in hippocampus and prefrontal cortex. Neuropharmacology 67: 144-154, 2013.

CHANG L, SMITH LM, LOPRESTI C, YONEKURA ML, KUO J, WALOT I, ERNST T: Smaller subcortical volumes and cognitive deficits in children with prenatal methamphetamine exposure. Psychiatry Res 132: 95-106, 2004.

CROZATIER C, GUERRIERO RM, MATHIEU F, GIROS B, NOSTEN-BERTRAND M, KOSOFSKY BE: Altered cocaine-induced behavioral sensitization in adult mice exposed to cocaine in utero. Brain Res Dev Brain Res 147: 97-105, 2003.

FRIEDMAN SD, CASTANEDA E, HODGE GK: Long-term monoamine depletion, differential recovery, and subtle behavioral impairment following methamphetamine-induced neurotoxicity. Pharmacol Biochem Behav 61: 3544, 1998.

GALLAGHER M, BURWELL R, BURCHINAL M: Severity of spatial learning impairment in aging: development of a learning index for performance in the Morris water maze. Behav Neurosci 107: 618-626, 1993.

HRUBÁ L, SCHUTOVÁ B, POMETLOVÁ M, ROKYTA R, ŠLAMBEROVÁ R: Effect of methamphetamine exposure and cross-fostering on cognitive function in adult male rats. Behav. Brain Res. 208: 63-71, 2010.

JANUS C: Search strategies used by APP transgenic mice during navigation in the Morris water maze. Learn Mem 11: 337-346, 2004.

KELLEY AE: Memory and addiction: shared neural circuitry and molecular mechanisms. Neuron 44: 161-179, 2004.

LUBBERS ME, VAN DEN BOS R, SPRUIJT BM: Mu opioid receptor knockout mice in the Morris Water Maze: a learning or motivation deficit? Behav Brain Res 180: 107-111, 2007.

MARTIN JC, MARTIN DC, RADOW B, SIGMAN G: Growth, development and activity in rat offspring following maternal drug exposure. Exp. Aging Res. 2: 235-251, 1976.

MARWICK C: NIDA seeking data on effect of fetal exposure to methamphetamine. JAMA 283: 2225-2226, 2000.

MELNICK SM, DOW-EDWARDS DL: Differential behavioral responses to chronic amphetamine in adult male and female rats exposed to postnatal cocaine treatment. Pharmacol Biochem Behav 69: 219-224, 2001.

MOENK MD, MATUSZEWICH L: Juvenile but not adult methamphetamine exposure improves performance in the Morris Water Maze in male rats. Int J Dev Neurosci 30: 325-331, 2012.

MORRIS RG, GARRUD P, RAWLINS JN, O'KEEFE J: Place navigation impaired in rats with hippocampal lesions. Nature 297: 681-683, 1982.

PERIS J, DECAMBRE N, COLEMAN-HARDEE ML, SIMPKINS JW: Estradiol enhances behavioral sensitization to cocaine and amphetamine-stimulated striatal [3H]dopamine release. Brain Res 566: 255-264, 1991.

PERIS J, COLEMAN-HARDEE M, MILLARD WJ: Cocaine in utero enhances the behavioral response to cocaine in adult rats. Pharmacol Biochem Behav 42: 509-515, 1992.

RICE D, BARONE S Jr: Critical periods of vulnerability for the developing nervous system: evidence from humans and animal models. Environ Health Perspect 108 (Suppl 3): 511-533, 2000.

ROTH ME, CASIMIR AG, CARROLL ME: Influence of estrogen in the acquisition of intravenously self-administered heroin in female rats. Pharmacol Biochem Behav 72: 313-318, 2002.

SALAMONE JD, CORREA M: Motivational views of reinforcement: implications for understanding the behavioral functions of nucleus accumbens dopamine. Behav Brain Res 137: 3-25, 2002.

SCHINDLER CW, BROSS JG, THORNDIKE EB: Gender differences in the behavioral effects of methamphetamine. Eur J Pharmacol 442: 231-235, 2002.

SCHUTOVÁ B, HRUBÁ L, POMETLOVÁ M, DEYKUN K, ŠLAMBEROVÁ R: Impact of methamphetamine administered prenatally and in adulthood on cognitive functions of male rats tested in Morris water maze. Prague Med Rep 109: 62-70, 2008.

SCHUTOVÁ B, HRUBÁ L, POMETLOVÁ M, DEYKUN K, ŠLAMBEROVÁ R: Cognitive functions and drug sensitivity in adult male rats prenatally exposed to methamphetamine. Physiol Res 58: 741-750, 2009.

SCHUTOVÁ B, HRUBÁ L, ROKYTA R, ŠLAMBEROVÁ R: Gender differences in behavioral changes elicited by prenatal methamphetamine exposure and application of the same drug in adulthood. Dev Psychobiol 55: 232$242,2013$. 
SELL SL, SCALZITTI JM, THOMAS ML, CUNNINGHAM KA: Influence of ovarian hormones and estrous cycle on the behavioral response to cocaine in female rats. J Pharmacol Exp Ther 293: 879-886, 2000.

ŠLAMBEROVÁ R, POMETLOVÁ M, SYLLABOVÁ L, MANČUŠKOVÁ M: Learning in the Place navigation task, not the New-learning task, is altered by prenatal methamphetamine exposure. Brain Res Dev Brain Res 157: 217-219, 2005.

ŠLAMBEROVÁ R, POMETLOVÁ M, CHAROUSOVÁ P: Postnatal development of rat pups is altered by prenatal methamphetamine exposure. Prog Neuropsychopharmacol Biol Psychiatry 30: 82-88, 2006.

ŠLAMBEROVÁ R, SCHUTOVÁ B, HRUBÁ L, POMETLOVÁ M: Does prenatal methamphetamine exposure affect the drug-seeking behavior of adult male rats? Behav Brain Res 224: 80-86, 2011 a.

ŠLAMBEROVÁ R, YAMAMOTOVÁ A, SCHUTOVÁ B, HRUBÁ L, POMETLOVÁ M: Impact of prenatal methamphetamine exposure on the sensitivity to the same drug in adult male rats. Prague Med Rep 112: 102114, 2011b.

SMITH LM, CHANG L, YONEKURA ML, GROB C, OSBORN D, ERNST T: Brain proton magnetic resonance spectroscopy in children exposed to methamphetamine in utero. Neurology 57: 255-260, 2001.

STANWOOD GD, LEVITT P: Repeated i.v. cocaine exposure produces long-lasting behavioral sensitization in pregnant adults, but behavioral tolerance in their offspring. Neuroscience 122: 579-583, 2003.

SUZUKI T, FUKUOKA Y, MORI T, MIYATAKE M, NARITA M: Behavioral sensitization to the discriminative stimulus effects of methamphetamine in rats. Eur J Pharmacol 498: 157-161, 2004.

TURNER CD, BAGNARA JT: Endocrinology of the ovary. General Endocrinology. W. B. Saunders Company, Philadelphia, 1976, pp 450-495.

VAVŘíNKOVÁ B, BINDER T, ŽIVNÝ J: Characteristics of a population of drug dependent pregnant women in the Czech Republic. (in Czech) Ceska Gynekol 66: 285-291, 2001.

VORHEES CV, INMAN-WOOD SL, MORFORD LL, BROENING HW, FUKUMURA M, MORAN MS: Adult learning deficits after neonatal exposure to D-methamphetamine: selective effects on spatial navigation and memory. $J$ Neurosci 20: 4732-4739, 2000.

VORHEES CV, REED TM, MORFORD LL, FUKUMURA M, WOOD SL, BROWN CA, SKELTON MR, MCCREA AE, ROCK SL, WILLIAMS MT: Periadolescent rats (P41-50) exhibit increased susceptibility to D-methamphetamine-induced long-term spatial and sequential learning deficits compared to juvenile (P21-30 or P31-40) or adult rats (P51-60). Neurotoxicol Teratol 27: 117-134, 2005.

WARREN SG, JURASKA JM: Spatial and nonspatial learning across the rat estrous cycle. Behav Neurosci 111: 259266, 1997.

WILLIAMS MT, BLANKENMEYER TL, SCHAEFER TL, BROWN CA, GUDELSKY GA, VORHEES CV: Longterm effects of neonatal methamphetamine exposure in rats on spatial learning in the Barnes maze and on cliff avoidance, corticosterone release, and neurotoxicity in adulthood. Dev Brain Res 147: 163-175, $2003 \mathrm{a}$.

WILLIAMS MT, MORAN MS, VORHEES CV: Refining the critical period for methamphetamine-induced spatial deficits in the Morris water maze. Psychopharmacology (Berl) 168: 329-338, $2003 \mathrm{~b}$. 